\title{
Religião e psicanálise no Brasil contemporâneo: novas e velhas Weltanschauungen
}

\author{
Luiz F. D. Duarte \& Emilio N. de Carvalho \\ Professor do Programa de Pós-graduação em Antropologia Social \\ do Museu Nacional - UFRJ \\ Doutorando do Programa de Pós-graduação em Antropologia Social \\ do Museu Nacional - UFRJ
}

RESUMO: A presença da psicanálise, como saber e instituição, modificouse bastante no Brasil, desde o final dos anos 1970, quando sua presença e influência visíveis na sociedade e na cultura nacionais tinham atingido o seu auge. Diversas análises recentes apontam para uma descentralização, diversificação e complexificação da oferta psicoterapêutica; ao mesmo tempo em que se reconhece um intenso recrudescimento da oferta de recursos religiosos ou para-religiosos. Inicialmente, esse reconhecimento se concentrou nas alternativas associáveis ao estilo Nova Era, características das camadas médias metropolitanas, que podem ser - frequentemente - consideradas como variações de uma cultura psicologizada. $\mathrm{O}$ crescimento da adesão às seitas pentecostais, principal característica dos desenvolvimentos religiosos nas camadas populares, parecia seguir uma outra lógica, também fartamente estudada. Mais recentemente, surgiram mediaçōes entre as religiōes evangélicas e pentecostais e a psicanálise que provocaram grande surpresa e inquietação nos meios intelectuais. O diálogo entre a pesquisa de Carvalho sobre esse último processo e a pesquisa de Duarte sobre a dinâmica das cosmologias (Weltanschauungen) religiosas e laicas em confronto na sociedade brasileira contemporânea permite apresentar novas interpretações desse quadro dinâmico.

PALAVRAS-CHAVE: religião, psicanálise, protestantismo, pentecostalismo, psicologização. 
Duarte, L. F. D. \& Carvalho, E. N. Religiāo e psicanálise no Brasil...

\section{Introdução}

A entrada e difusão da psicanálise no Brasil são consideradas como uma das dimensões do processo de "modernização" da nação, associada à expectativa de predomínio do conhecimento científico na regulação da vida social e à substituição das construçóes religiosas da pessoa por uma interiorização laica e racionalizada. Seus seguidores explícitos iniciais foram médicos, sobretudo psiquiatras, do período do entre-guerras, seguidos por artistas de vanguarda e pelos psicólogos de formação universitária emergentes nos anos 1960-1970. Sua presença imaginária esteve comumente associada à dessacralização da vida moral e da preeminência da autoridade familiar, expressa, por exemplo, nas acusaçôes de "pansexualismo", bastante difundidas nos meios católicos e protestantes.

A circulação relativamente restrita ${ }^{1}$ que a caracterizou até os anos 1960 ampliou-se radicalmente na década seguinte, ensejando um consumo mediato e imediato do conhecimento e da prática terapêutica psicanalíticos amplamente presente nas classes médias e superiores metropolitanas. Formulou-se então o diagnóstico de uma "explosão da psicanálise", relacionada com os efeitos da modernização socioeconômica acelerada após a Segunda Grande Guerra e da modernização ideológica associável à difusão dos movimentos contraculturais. Esse fenômeno suscitou uma ampla literatura interpretativa, que se beneficiou de um diálogo intenso dos próprios psicanalistas com as ciências sociais nacionais em fase de consolidação institucional (cf. Figueira, 1985; Russo, 1999; Duarte, 2000).

A presença da psicanálise, como saber e como instituição, vem se modificando bastante no Brasil desde o final dos anos 1970, quando sua presença e influência visíveis na sociedade e na cultura nacionais tinham atingido o seu auge. Diversas análises recentes apontam para uma descentralização, diversificação e complexificação muito grandes da ofer- 
Revista de Antropologia, São Paulo, USP, 2005, v. 48 No 2.

ta psicoterapêutica; ao mesmo tempo em que se reconhece um intenso recrudescimento da oferta de recursos religiosos ou parareligiosos. Inicialmente, esse reconhecimento se concentrou nas alternativas associáveis ao estilo Nova Era, características das camadas médias metropolitanas, que são às vezes consideradas como variações de uma cultura psicologizada. Também se descreve um revigoramento notável da psiquiatria biologizante no Brasil, seguindo uma tendência mundial (por influência dos Estanos Unidos), hostil às interpretações psicogênicas do sofrimento mental.

O crescimento da adesão às igrejas pentecostais, principal característica dos desenvolvimentos religiosos nas camadas populares desde os anos 1970, seguiu uma outra dinâmica, também crescentemente estudada, de reavivamento mágico-religioso. Recentemente, tornaram-se mais visíveis as mediaçōes já existentes entre as religiōes evangélicas e pentecostais e a psicanálise (ou, pelo menos, os saberes psicológicos) que deslocaram também para esse plano as polêmicas sobre tradição e modernidade nesse segmento religioso.

Verificou-se, além do mais, que a proliferação de propostas de interpretação e terapêutica do sofrimento e da aflição, que podem ser consideradas como formações ideológicas transicionais ou híbridas entre os saberes psicológicos (ou psicologizantes) e as fórmulas mágico-religiosas, afeta não apenas as classes populares, mas também as classes médias e as elites. E nestas não se expressam apenas em "novos movimentos religiosos", mas afetam também, de dentro, as denominações tradicionais, inclusive a Igreja Católica.

O presente trabalho pretende apresentar uma visão geral do estado atual dessas relações entre os saberes psicológicos e a religiosidade no Brasil contemporâneo, baseada em pesquisas conduzidas pelos dois autores - o primeiro centrado nas relações entre religião, família e reprodução em diversos segmentos sociais da região metropolitana do Rio de 
Duarte, L. F. D. \& Carvalho, E. N. Religiāo e psicanálise no Brasil...

Janeiro, e o segundo centrado na organização interna do movimento de "psicanálise didática cristã "2 com base em uma rede institucional de âmbito nacional. A apresentação dos dados está englobada pelo esboço de uma interpretação mais abrangente da dinâmica desse campo unificado das terapêuticas psicológicas e religiosas e sobre sua relação com os estudos de construção social da Pessoa e da família na cultura ocidental moderna. Essa interpretação exige inclusive uma releitura da correlação linear oficial entre psicanálise e laicização, uma vez que as apropriações religiosas desse saber foram muito precoces, inclusive no Brasil.

\section{O campo psi no Brasil hoje}

O que é chamado de "campo psi" no Brasil e que abarca os saberes muito díspares abrigados sob as rubricas da psicologia, da psiquiatria e da psicanálise oferece um quadro de grande complexidade. Esses saberes não se concentram mais apenas nas grandes metrópoles pioneiras (Rio de Janeiro e São Paulo), mas se disseminam por todos os centros urbanos de alguma monta. Os cursos universitários de psicologia se encontram disseminados por todo o país e seus currículos oferecem uma gama muito variada de especializações, correntes e tendências. As formações médicas em psiquiatria também se multiplicaram, obedecendo a currículos muito diversificados em função das tradições locais. Mas é sobretudo a psicanálise que se organiza em uma trama complexa de instituições onipresentes, em contínua segmentação e reordenação. As relações entre esses saberes também obedecem a regimes muito variados, com algum tipo de psicanálise presente nos currículos de psicologia ou nos serviços públicos de psiquiatria e algum tipo de oposição à psicanálise presente nas formações em psiquiatria e em algumas linhas de especialização em psicologia ${ }^{3}$. 
Revista de Antropologia, São Paulo, USP, 2005, v. 48 № 2.

De um ponto de vista mais interno, pode-se reconhecer quatro grandes processos concomitantes desencadeados durante os anos 1970 (o apogeu mesmo da "explosão da psicanálise") e balizadores do campo durante a década seguinte: a intensa fragmentação institucional após um longo período de concentração em umas poucas instituições pioneiras; a psicanalização da formação psiquiátrica; a intensificação da formação de psicólogos (e a psicanalização concomitante); e a polarização do campo entre a ênfase filosófica dos lacanianos e a ênfase "corporal" dos reichianos (cf. Russo, 1990; 1993; 1997). Mesmo este último movimento, apesar de uma inicial retórica antipsicanalítica, mantinha ainda sua referência última ao pensamento freudiano.

Já se fazia perceber, no entanto, ao longo da década de 1980, a presença de uma série de outras ofertas terapêuticas não explicitamente psicológicas, herdeiras - tanto quanto o reichianismo - da Contracultura: toda essa miríade de orientalismos, ocultismos, esoterismos, naturalismos e experiências corporais que se veio a chamar oportunamente de movimentos "Nova Era" ou de "religiosidades do self" (cf. Heelas, 1996; Amaral, 2000; Magnani, 2000) e que se materializa eventualmente sob a forma da literatura chamada de "auto-ajuda" (cf. Salem, 1992). Essas novas ofertas simbólicas pareciam dirigir-se aos mesmos segmentos sociais consumidores das terapias psicanalíticas: as classes letradas, interiorizadas e individualizadas das grandes cidades. $\mathrm{O}$ tema da "autenticidade" continuava a dar a tônica cosmológica, embora o foco parecesse se deslocar da relação entre psiquismo e inconsciente para as dimensões mais imediatamente corporais, sentimentais e espirituais. Uma linha de interpretação prestigiosa tendeu a considerar esses desenvolvimentos não como propriamente antipsicológicos, mas como pós-psicológicos - no sentido de continuarem pressupondo, subjacente, a visão de mundo psicológica (cf. Russo, 2001). Poder-se-ia considerar como características dessa continuidade a preeminência de um subjetivismo 
Duarte, L. F. D. \& Carvalho, E. N. Religiāo e psicanálise no Brasil...

estruturante (sistemas de interpretação do mundo centrados em ego), a crença na existência de uma interioridade, a representação de uma dinâmica agonística dessa interioridade, o reconhecimento de uma dimensão obscura a esclarecer em seu âmago, a suposição de que esse âmago esteja relacionado com a experiência pessoal dos primeiros anos de vida (e eventualmente da vida intra-uterina), a disposição pragmática de dispor concomitantemente de diversos sistemas de interpretação e terapêutica (sem pressupor uma "conversão" religiosa exclusivista, por exemplo) e - sobretudo - o privilégio de uma salvação intramundana (cura, conscientização, insight, equilibrio interior etc.).

O mais novo componente desse quadro é a consolidação, nos meios psiquiátricos, das versões biologizantes da vida psíquica ou mental, em detrimento de uma longa hegemonia da visão psicanalítica. Diversos trabalhos têm analisado as características e conseqüências dessa crescente ênfase no localizacionismo cerebral, no determinismo genético e nas terapêuticas psicofarmacológicas, ressaltando a sua solidariedade com outros processos ideológicos em curso nas sociedades contemporâneas (cf. Henning, 2000; Russo \& Ponciano, 2002; Bezerra, 2002). É um processo que envolve uma "medicalização" certamente, mas sobretudo um retorno ao fisicalismo característico do projeto iluminista, fonte principal do cientificismo moderno. Essa tendência tem influenciado crescentemente o imaginário público, sobretudo com suas propostas de patologização do sofrimento ordinário (como no caso exemplar de uma "doença do pânico"), mas parece conviver ainda com a presença mediática da psicanálise e sua ênfase psicogênica. Um traço eminente dessa modalidade de entendimento do sujeito humano, em relação à que prevalecia sob a psicanálise, é o privilégio da exterioridade sobre a interioridade. Tem parecido útil a alguns intérpretes considerar que essa ênfase em um determinismo externo, corporal, pode conviver melhor 
com a preservação do ideal cristão tradicional do livre-arbítrio do que a representação de uma interioridade conflitiva e dinâmica, cuja lógica escapa ao domínio consciente ${ }^{4}$.

É possível que haja, como defende Jane Russo, uma afinidade entre o "alternativismo" Nova Era e a rebiologização da psiquiatria: ambos privilegiam um "monismo pelo corpo" em detrimento do caráter físicomoral das representaçôes da Pessoa consolidadas no Ocidente a partir do século XVIII. Mesmo a espiritualidade pós-psicológica pressuporia que "é através do corpo que se atinge o espiritual” (Russo, 2001, p. 122).

\section{A religiáo e a psicanálise como categorias de estudo}

Até o momento, utilizamos as categorias "religiāo" e "psicanálise" como se fossem unívocas e se referissem a fenômenos indiscutivelmente universais. Não cabe aqui portar tal discussão até seus limites extremos, mas convém sublinhar alguns pontos necessários a nossa análise. De um ponto de vista formal, o caso da "psicanálise" é mais simples, já que seguimos, em princípio, a convenção antropológica de respeitar as classificações nativas. Como os nativos não estão, porém, de acordo entre si a esse respeito, é preciso acrescentar moduladores que expressem a dissensão presente no campo em torno do uso da categoria (é o caso de "psicanálise didática cristã”, por exemplo). De um ponto de vista mais substantivo, pode-se preferir a referência - como fizemos eventualmente - a "saberes psicológicos" ou "psicologizantes", sempre que isso seja útil para significar um universo mais abrangente de fenômenos aparentados.

O caso da categoria "religião" é mais crítico, já que não é relevante a nosso ver - o critério formal: nem todas as formações ideológicas que parecem aos membros de nossa cultura ser "religiōes" são consideradas 
Duarte, L. F. D. \& Carvalho, E. N. Religiāo e psicanálise no Brasil...

emicamente como religióes e, eventualmente, o que parece ser obviamente uma "religião", a nossos olhos, pode ter esse estatuto negado por um fiel em função de conotações históricas dessa categoria. É, por outro lado, crucial atentar para a sua dimensão substantiva, sobretudo porque não há consenso nas ciências humanas a respeito do que a categoria "religião" designa ou conota de universal ou de essencial na experiência humana.

A convenção aqui seguida é a da acepção durkheimiana de religião como "representação da totalidade", ou seja, como aquilo que pode também ser chamado de "visão de mundo" ou de "cosmologia". A utilização dessa convenção para a análise das sociedades modernas nos leva a uma consideração paradoxal: a configuração de valores (nem sempre coerente e unívoca) que preside à ordenação da cultura ocidental moderna não se apresenta como "religiosa", muito ao contrário inscreve-se numa longa luta de afirmação de sua condição laica. Se considerarmos que as categorias de "subjetivismo" e de "naturalismo" - que defendemos recentemente como capazes de descrever o núcleo ideológico dessa configuração (cf. Duarte et al., 2006) - são as mais abrangentes e estruturantes que se possa reconhecer, somos levados a considerar que elas compõem uma "religiosidade" laica ou, pelo menos, não confessional, englobante de todas as fórmulas de totalização específicas das confissões religiosas - não sem contradições ou conflitos.

Levantamos ainda a hipótese - nesse sentido - de que é o modo de aproximação desses valores estruturantes, a disposição de ethos assim abraçada pelos sujeitos sociais nas sociedades liberais modernas, que os impele a uma aproximação a tal ou qual opção confessional, à eventual adoção de uma reserva subjetiva em relação às determinações de sua religião atribuída, ou à disposição de viver afastado de qualquer instituição religiosa formal - e não o oposto, como habitualmente se concebe. 
Revista de Antropologia, São Paulo, USP, 2005, v. 48 no 2.

A existência de um ethos hegemônico laico abrangente já mereceu a atenção de diversos autores, desde que Durkheim se referiu a um "culto do eu" como característico da religiosidade de seu tempo na França letrada (cf. Durkheim, 1968). Duas tendências aí se apresentam: a que busca demonstrar a qualidade estruturante e culturalmente determinada dos valores laicos da cultura ocidental moderna a partir de dentro (cf. Rieff, 1968; Duarte, 1983) e a que - mais recentemente - busca relativizar a disposição universalizante desses valores a partir de outras tradiçōes culturais (cf. Bahmanpour, 2003). O próprio tema da "civil religion" estado-unidense, analisado por Robert Bellah (1967), não deixa de se aparentar com a religiosidade laica aqui mencionada, embora enfatize antes o ethos público que o privado.

A perspectiva da convivência de religiosidades convencionais e "laicas" visa facilitar a compreensão do conjunto dos fenômenos sociais característicos da construção da pessoa e de seu ethos público e privado nas sociedades ocidentais modernas (e, possivelmente, em muitas outras contemporâneas). Ela não pode ignorar a especificidade das ideologias que se pretendem explicitamente religiosas, do ponto de vista institucional, cosmológico e ético, mas tampouco pode considerar as representações nativas como um impedimento a uma análise universalizante de suas características culturais.

É preciso, porém, reconhecer que esse sistema de valores não escapa à condição de religiosidade laica, característica aqui examinada dos valores modernos. O pensamento científico contém ao mesmo tempo, paradoxalmente, as características acima apontadas de um movimento ideológico anti-religioso e as características de uma visão de mundo abrangente, comprometida com uma representação totalizante e com uma ética exclusivista - o universo é cognoscível justamente porque seu conhecimento não é dado a priori e só pode ser atingido por indução controla- 
Duarte, L. F. D. \& Carvalho, E. N. Religião e psicanálise no Brasil...

da. A psicanálise proposta por Freud é uma das herdeiras mais típicas dessa complexa disposição cultural, ainda mais por se voltar justamente para a vida moral, psicológica, subjetiva, humana (cf. Freud, 1976).

É preciso levar ainda em conta que as religiões ocidentais não têm uma relação uniformemente antagônica ao "pensamento científico" nem tampouco mantiveram a mesma atitude a respeito de todas as suas dimensões ao longo dos últimos três séculos. Os saberes psicológicos, por exemplo, parecem dever ao protestantismo a sua formalização como área desencantada de pesquisa e ensino acadêmico ainda no século XVI (cf. Vidal, 2000). A famosa obra de William James (1958) sobre a experiência religiosa é, ao mesmo tempo, um marco na compreensão fenomenológica desse fenômeno e um testemunho de seu arraigado horizonte cultural protestante.

Uma das reações acolhedoras mais precoces à obra de Freud adveio de um pastor protestante, mesmo que o "pai da psicanálise" tenha manifestado sua recorrente preocupação em relação à leitura pastoral ou didática feita por Oscar Pfister ${ }^{5}$ - no contexto de um longo e cordial diálogo (cf. Birman, 1984). Carl Gustav Jung era filho de um pastor protestante - fato que pode ser aduzido tanto à hipótese de uma afinidade possível entre a visão reformada da pessoa e a proposta freudiana quanto à de que conduziu à construção de uma versão "religiosa" da psicanálise (cf. Rieff, 1968).

Não se trata, de qualquer modo, de dissolver a especificidade das ideologias laicas do Ocidente moderno (inclusive a da psicanálise tal como concebida por Freud) em relação às ideologias religiosas. Trata-se de reconhecer a complexidade de sua inter-relação sem garantir, a uma ou a outra, privilégios de extraterritorialidade cultural e de levar em conta que - de um ponto de vista antropológico - ambos os tipos de ideologias exigem alguma forma de "doutrina" e dependem da "adesão", do "pertencimento" e de um "ethos", socialmente construídos, de seus fiéis. 


\section{Focos comparados de pessoa, religião e psicologia no Brasil hoje}

O campo religioso brasileiro, tradicionalmente caracterizado pela hegemonia do catolicismo herdado da colonização portuguesa, também passou por um processo de intensa complexificação nas três últimas décadas do século XX. Essas transformações consistiram sobretudo em três processos concomitantes: a institucionalização das Comunidades Eclesiais de Base (CEBs), um importante movimento de ação e intervenção social mantido por alguns segmentos subordinados da Igreja Católica; a proliferação de denominaçōes pentecostais, a subseqüente e acelerada expansão de sua membresia e a intensificação de movimentos de renovação nas igrejas protestantes históricas; $\mathrm{e}$ - finalmente - o surgimento e expansão de um movimento de renovação carismática no interior da Igreja Católica.

Os movimentos de reavivamento brasileiros acompanham tendências do cristianismo norte-americano, tanto em sua vertente evangélica quanto católica. Sua principal característica cosmológica é a da experiência imediata da possessão pelo Espírito Santo, desafiadora das confissōes cristâs estabelecidas que repousam sobre um longo processo de burocratização do carisma, indissociável da racionalização do mundo implicada na ordem cultural ocidental moderna. A segunda característica é a de um alto grau de exclusivismo religioso, imediatamente oponente do tradicional sincretismo vertical brasileiro, assim como das dimensóes mágicas do catolicismo, particularmente do popular. A terceira característica é a de uma mais explícita e radical intramundanidade que se expressa exemplarmente na chamada Teologia da Prosperidade (que não é compartilhada por todas as tendências). A quarta característica é a de que a desmagicização prevalecente (indissociável do exclusivismo) não impede algumas de suas denominações de uma relação interna direta e explí- 
Duarte, L. F. D. \& Carvalho, E. N. Religião e psicanálise no Brasil...

cita com os alvos de sua luta ideológica, sobretudo os cultos afro-brasileiros. Os intérpretes desse movimento mantêm acesa polêmica sobre sua identidade: um protestantismo sem ascese e sem salvação extramundana, uma eticização com possessão, um exclusivismo desencantado que não exclui continuidades sincréticas (cf. Birman, 1996; Mariz \& Machado, 1994).

Um ponto muito comum em todo o campo é o da representação de um continuum de formas religiosas ordenado segundo um princípio de maior ou menor espiritualidade. Essa representação só constitui um ponto de doutrina explícito para o espiritismo kardecista, no qual avulta a representação, típica do evolucionismo romântico, de um processo geral de passagem da matéria para o espírito, do bruto para o elaborado, do simples para o complexo, do terreno para o transcendente. Não se está longe do "processo civilizatório" eliasiano, porém com uma ênfase mais linear no Geist. Muitos informantes, de diferentes confissōes religiosas, apresentam, no entanto, sinais dessa representação, que se poderia considerar como o oposto de um exclusivismo e, portanto, como um patamar mínimo de sincretismo, em que todas as experiências religiosas têm um fundamento transcendente real, embora localizadas em pontos diferentes de um arco de espiritualidade crescente ${ }^{6}$. Há, porém, diferenças importantes na maneira de afirmá-lo, encontrando seu limite na demonização brandida pelos pentecostais contra as "entidades" dos cultos afro-brasileiros. No outro extremo, estariam os consumidores da Nova Era, tolerantes em relação ao conjunto e pessoalmente disponíveis para muitos pontos do espectro, na dependência de juízos de autenticidade subjetiva e oportunidade conjuntural. Eles não deixariam, no entanto, de compartilhar da representação de um continuum de espiritualidade crescente.

A perspectiva abrangente de "religiosidade" aqui privilegiada sugere que se observe sucessivamente uma série de focos etnográficos presentes 
Revista de Antropologia, São Paulo, USP, 2005, v. 48 no 2.

nas pesquisas dos autores ou encontráveis na literatura antropológica contemporânea que permitam situá-la e analisá-la.

O primeiro foco é o mais abrangente e também o menos explícito. Trata-se do núcleo de valores que é axial em torno da relação entre o sujeito e a família. Como foi tematizado por Duarte em outros trabalhos, a instituição da "família" moderna é inseparável da constituição do valor ideológico do "indivíduo" na cultura ocidental (cf. Duarte et al., 2006). Pode-se considerar mesmo que seja o seu traço institucional distintivo o mandamento de produzir "indivíduos" livres, iguais e autônomos, com todas as contradições que se impõem a tal tarefa.

$\mathrm{Na}$ medida em que a construção do indivíduo moderno implica um verdadeiro "culto do eu" (cf. Durkheim, 1968; Duarte, 1983), não é surpreendente que a própria família em que emerge se veja revestida de um caráter sacralizado, como fons et origo do novo sujeito. Entre as diversas dimensóes dessa sacralidade, que ultrapassa de muito o tema deste artigo, interessa-nos a relação que mantém com a "psicologização" enquanto teoria e prática da interioridade subjetiva. A psicanálise, mais do que qualquer outro saber erudito moderno, contribuiu para aureolar o "parental" de um caráter mágico intrínseco, estruturante - lugar a que se atribui a articulação dos nódulos essenciais de qualquer subjetividade. É claro que, ao fazê-lo, ela seguiu a trilha ideológica dos investimentos precedentes no "familismo" moderno, acumulados desde meados do século XVIII. As religiōes cristãs constituíram o principal comutador desses valores, em sua forma positiva linear e apologética, por meio de uma intensa pastoral de afirmação do primado da "célula mater da sociedade". A psicanálise, herdeira das ambigüidades românticas, inovou ao dotar o culto à família de um componente inquietante, "sinistro", unheimlich, que o tornou mais substancialmente não laico, sagrado. Esse culto é inseparável da experiência subjetiva das classes letradas modernas e sua presença avulta na sociedade brasileira, nos segmentos marca- 
Duarte, L. F. D. \& Carvalho, E. N. Religião e psicanálise no Brasil...

dos pela "interiorização". A experiência das terapias psicanalíticas está fortemente associada a um "culto do eu" que se desenvolve no "sacrário da família” ou, melhor dizendo, do sentimento da família, já que não se trata tanto da experiência social concreta dessa instituição quanto da sua vivência interior.

Bem mais óbvia do que essa religiosidade interna à experiência da família psicologizada é a da referida panóplia de recursos simbólicos a que se faz referência sob a rubrica da Nova Era. Ela é também inseparável do "culto do eu" - e, no limite, do "sacrário familiar", embora em níveis e condições muito díspares. Muitas pesquisas contemporâneas têm se debruçado sobre pontos específicos dessa configuração, fornecendo material inesgotável para sua interpretação. Mais uma vez, nosso interesse aqui é o de ressaltar a importância geral da psicologização no contexto dessas religiosidades, mais do que o de revisar sua extensa etnografia. $\mathrm{O}$ trabalho pioneiro de Tania Salem é explícito ao nomear uma das tendências da bibliografia de auto-ajuda por ela examinada como "psicológica” (por oposição à “esotérica”) (cf. Salem, 1992, p. 2). O psicologismo é aliás explícito pela referência regular a diversas correntes das psicologias modernas, inclusive à psicanálise. Mais do que isso, porém, esses manuais comprometem-se com o que a autora chamou de "indivíduo natural", como indeterminação absoluta e originária, sobre a qual se pode instalar - desde que corretamente propiciado e cultivado - o reino do "livre-arbítrio" (id., p. 11). Nos manuais mais "esotéricos", nos termos da autora, esse livre-arbítrio é uma expressão direta de uma transcendência cósmica, hipóstase igualitária do indivíduo.

Entre o universo da "auto-ajuda" e o da Nova Era, parece se localizar a literatura da "cura interior" evangélica examinada por Lewgoy (2005), que se dissemina amplamente no Brasil. Essa literatura, de origem sobretudo norte-americana, é - segundo o autor - de consumo crescente entre os fiéis das denominações protestantes tradicionais e entre os sa- 
cerdotes das denominaçôes pentecostais brasileiras, por meio de traduções propiciadas por editoras evangélicas nacionais. Trata-se de um universo bastante amplo de formas literárias, estilos pastorais e fontes ideológicas, marcado pelo que o autor chama de "hibridização entre religião e psicologia” (id., p. 17). Considera-se que se venha desenvolvendo no mercado cultural norte-americano desde os anos 1970, o que faz supor que se nutra das mesmas imposições de mudança ideológica que presidiram à emergência da Contracultura e da Nova Era. Apresenta-se em rubricas confessionais tais como a da "vida cristã", "crescimento espiritual" e "confissão positiva", envolvendo categorias freqüentemente evocadas, como a de "auto-estima" e "autodesenvolvimento". A preeminência do valor do "bem-estar" (well-being) sugere uma aproximação com a Teologia da Prosperidade. Os intérpretes desses movimentos, citados por Lewgoy, chegam a falar em "Christian self-help" (cf. Hunter, 2000) e em "Nova Era evangélica".

Uma outra fonte tópica de informação sobre os meandros da psicologização no universo religioso brasileiro é a pesquisa de Carlos Steil com o Centro São José, um segmento do Movimento de Renovação Carismática Católica, sediado na cidade de Porto Alegre, que ele calcula atingir cerca de 5 mil pessoas, majoritariamente de classe média (cf. Steil, 2006). Esse movimento postula que a existência humana corrente é precedida por uma fase intra-uterina em que se cristaliza o destino de cada pessoa em relação com "condicionamentos" herdados das gerações anteriores. Esse destino pode ser alterado por meio de técnicas "psíquicomísticas" (nos termos do autor), que visam a "libertação" desses "demônios de geração".

$\mathrm{O}$ autor considera que o movimento envolve uma relativa "psicologização", em sua associação de temas Nova Era com os saberes biológicos e médicos contemporâneos, sob o guarda-chuva da renovação carismática católica. Efetivamente, parece prevalecer aí a idéia da busca de 
Duarte, L. F. D. \& Carvalho, E. N. Religiāo e psicanálise no Brasil...

um "verdadeiro eu" a ser atingido através de um "aperfeiçoamento interior gradativo", envolvendo "corpo, mente e espírito". A mundanidade mais uma vez hegemônica se expressa na idéia de uma "conscientização para melhor". Uma peculiar "psicologização" pode ser entrevista na representação de uma patologia mental decorrente da relação do sujeito com seus antepassados e de uma terapêutica mental capaz de superar os entraves dessa herança geracional.

Essa peculiar psicologização em curso nos meios carismáticos contemporâneos pode ser melhor entendida à luz das informações gerais que fornece Pierre Sanchis (2006) sobre as relações entre a Igreja Católica e a psicanálise no Brasil. Ele ressalta como essas relações se estreitam a partir dos anos 1950, sob a influência de uma tendência revivalista na formação sacerdotal, atingindo seu ápice na seqüência do Concílio Vaticano II. Diversas iniciativas específicas foram importantes nesse período, como o Centro de Estudos Freudiano, constituído por um grupo de religiosos e considerado pelo Dicionário de Psicanálise de Roudinesco \& Plon como o primeiro círculo lacaniano do Brasil (1975). Outro exemplo dessas relaçoes foi a criação do Círculo Brasileiro de Psicanálise, em 1956, por um padre católico que fez psicanálise didática em Viena com Igor Caruso. Informa Sanchis ainda que, "em 1963, se transferiu para Belo Horizonte, dando início ao Círculo Psicanalítico de Minas Gerais. Tendo permanecido nos quadros do clero secular, dedica-se hoje à hipnoterapia e à hipnoanálise" (p. 30). Um terceiro exemplo é o curso Christus Sacerdos, instituído por volta de 1970 pelos jesuítas em seu colégio de São Leopoldo, com a finalidade de formação de quadros sacerdotais.

Tratava-se de um ciclo de formação que visava articular as contribuições da sociologia, da teologia e da psicologia. Segundo as lembranças de um cursista, contudo, "a ênfase era muito mais na vivência psicanalítica que 
Revista de Antropologia, São Paulo, USP, 2005, v. 48 № 2.

na teologia, dogmática ou moral, embora mais na dogmática que na moral”. Era sistemática a análise individual dos cursistas por psicanalistas da cidade. (Sanchis, 2006, p. 31)

Alguns carmelitas, ex-alunos desse curso, fundaram, em 1972, o Centro de Integração Psicoteológica (CIPT) para religiosos(as), aberto em seguida também a leigos, que mesclava horizontes de formação pastoral e terapia analítica (ou psicológica).

Uma outra dimensão extremamente importante das relações entre psicanálise e religião no Brasil hoje é a da já citada "psicanálise didática cristã". São assim nomeadas as iniciativas que associam o treinamento em psicanálise e o uso de terapias psicanalíticas a contextos religiosos mais ou menos explícitos. A pesquisa de Carvalho tem se centrado na compreensão desse universo, por meio de redes sociais aglutinadas nas cidades de São Paulo, Rio de Janeiro e Belo Horizonte, embora remetam para um contexto nacional. Trata-se de compreender o investimento de pastores evangélicos nos saberes e nas práticas psicanalíticas através de novos cursos de psicanálise com tempo reduzido de formação. Esse fenômeno tem suscitado inúmeros casos jurídicos e institucionais que o transformaram numa das questões mais polêmicas do campo "psi”" brasileiro contemporâneo ${ }^{7}$.

No caso dos saberes e das práticas da psicanálise, entretanto, essa difusão no campo evangélico brasileiro foi mais lenta e inicialmente tímida, permanecendo por mais tempo restrita a subtópicos de disciplinas acadêmicas nos cursos de graduação e pós-graduação em teologia e ciências da religião ${ }^{8}$. Assim, é somente em meados da década de 1990 que a Sociedade Psicanalítica Ortodoxa do Brasil (SPOB, fundada em 1994) lança um projeto nacional de difusão da psicanálise a partir de um novo estilo de formação de profissionais psicanalistas em prazos mais curtos e com preços mais acessíveis. Esse movimento de difusão da psi- 
Duarte, L. F. D. \& Carvalho, E. N. Religiāo e psicanálise no Brasil...

canálise foi rapidamente ampliado para além dos limites nacionais e para além da SPOB, através de inúmeras outras instituições de formação fundadas a partir do final da década de 1990, tais como a Associação Nacional de Psicanálise Clínica (ANPC), o Instituto Freud, a Academia Brasileira de Psicanálise Clínica (ABPC), a Sociedade Latino-Americana de Psicanálise Clínica (SLAPSIC) etc.

Pelo menos duas características iniciais estão presentes nessas instituições: a oferta de cursos de formação em teoria e clínica psicanalítica com duração variável entre um e dois anos, e guiados por mecanismos de avaliação-diplomação por coeficiente de rendimento; e uma diretoria vinculada a movimentos religiosos (quase sempre evangélicos).

O ponto mais marcante, entretanto, refere-se ao grande crescimento do número de cursos de psicanálise organizados por essas instituiçóes de formação, que assumiram como meta difundir a prática da psicanálise por todo o território brasileiro. Só a SPOB formou, entre 1996 e 2002, mais de 3 mil psicanalistas em todo o território nacional, ampliando ainda mais seu potencial de formação nos anos seguintes. Para se ter uma idéia dos números comparativos, a Associação Brasileira de Psicanálise - vinculada à International Psycho-Analytical Association (IPA) formou cerca de 980 psicanalistas até o ano de 2001, quando completou 49 anos de existência no Brasil (cf. Bloch, 2001). Os cursos de psicanálise vinculados à IPA possuem uma duração média de cinco a oito anos.

\section{A "psicologização" e o "reencantamento do mundo": velhas e novas perspectivas}

Embora a psicanálise seja apenas um dos muitos modelos de pessoa e perturbação que constituíram os saberes psicológicos em nossa cultura, ela deteve, desde o início de sua divulgação, um papel crítico no campo. 
Revista de Antropologia, São Paulo, USP, 2005, v. 48 № 2.

Com efeito, a proposta freudiana radicalizava os pressupostos permeantes da psicologização, concedendo-lhes um estatuto ontológico, epistemológico e terapêutico de grande coerência e atratividade cultural.

Uma breve revisão desses pressupostos nos faz retornar a algumas referências anteriores. A primeira é a do subjetivismo ou individualismo intrínsecos ao processo. Só uma visão do humano como centrado no indivíduo livre, igual e autônomo poderia ter suscitado a elaboração de um saber específico sobre a mente individual. A segunda referência é certamente à mundanização (e relativa desmagicização) implicada nesse subjetivismo. Só uma considerável ênfase na determinação da vida humana por fatores terrenos poderia igualmente ter suscitado que técnicas de interpretação e intervenção não religiosas pudessem ser consideradas dignas e razoáveis. Essa subjetividade intramundana deve ser dotada de uma interioridade, ou seja, de uma localização no interior do sujeito individual - e passa-se a considerar possível a modelização de sua constituição e dinâmica. Na medida em que é dotada de uma dinâmica, começa a se apresentar também como dotada de uma historicidade - e, portanto, de uma origem e de um destino imanentes. Na medida em que é dotada de uma constituição, pode acolher - por outro lado - a definição de forças moventes, eventualmente contraditórias entre si. Como se trata de um lugar ocupado pelo próprio sujeito, é necessário e possível passar pela própria subjetividade para aceder à sua eventual objetivação (o que se chamou às vezes de "método da introspecção").

A psicanálise freudiana se apóia sobre todos esses pressupostos cosmológicos e os reorganiza em torno de uma nova lógica. O primeiro ponto diacrítico é o da preeminência da dimensão inconsciente da vida psíquica sobre a dimensão consciente. $\mathrm{O}$ segundo, o da articulação da constituição e da dinâmica internas em torno do desejo sexual ou da sexualidade. $\mathrm{O}$ terceiro, o da exigência de comprometimento interiorizado do terapeuta (e de seu próprio inconsciente) na relação com o pa- 
Duarte, L. F. D. \& Carvalho, E. N. Religiāo e psicanálise no Brasil...

ciente: a teoria da transferência e da contratransferência. Nem o pensamento de Freud nem o desenvolvimento ulterior da psicanálise se resumem a isso, mas se pode possivelmente considerar que sejam pontos de grande consenso nas versões hegemônicas desse saber. A ênfase nesses mesmos três pontos pôde variar grandemente, mantendo-se porém a referência básica.

A tradição cristã, sobretudo a reformada, é inseparável do processo de constituição da noção de pessoa que acabamos de descrever como "psicologizada", embora a subsuma a uma determinação última transcendente. Pode-se dizer que há assim, portanto, como já mencionamos, uma verdadeira afinidade cultural entre a tradição religiosa central do Ocidente e a psicologização. $\mathrm{O}$ mesmo não se pode dizer da versão psicanalítica desse movimento. Nem a preeminência do inconsciente, nem a da sexualidade, nem a da implicação do terapeuta podem se adequar automaticamente a visões de mundo que reservam um papel preponderante para o livre-arbítrio individual, para uma determinação transcendente da vida moral e para uma atitude pastoral diretiva e didática9 ${ }^{9}$.

Ao defender a impossibilidade de vir a psicanálise a se apresentar como uma Weltanschaunng, dadas suas características de uma ideologia "científica", Freud vinha a se opor a um modelo de religião altamente estruturada e de simbolização rigorosamente fechada que correspondia certamente à representação estereotipada dos fiéis da racionalização modernizante ocidental. Mesmo assim, ele concedia que a crença na ciência em geral podia redundar numa Weltanschauung "científica”, contraditória figura híbrida entre a racionalização segmentada e a totalização de sentido a priori. Apenas a psicanálise se preservaria nesse contexto.

O conhecimento etnográfico e histórico de que se dispõe hoje sobre os sistemas de representação permite certamente uma compreensão mais nuançada, em que as visões de mundo religiosas não podem ser consideradas monolíticas, estáveis ou isentas de reflexividade, assim como as 
visões de mundo científicas não podem ser consideradas culturalmente neutras e absolutamente racionalizadas. Trata-se assim de compreender um campo social extremamente complexo, em que os tipos ideais tradicionais se expressam de modo particularmente díspar. Isso não significa porém ausência de estrutura, puro fluxo de formas arbitrárias. Apontamos aqui para algumas das linhas de força presentes no campo e para sua complexa e - às vezes - contraditória imbricação. O subjetivismo foi particularmente mencionado, pulsante sob as mais variadas formulações cosmológicas, seguindo a trilha da individualização, interiorização e psicologização. Segue-o a intramundanidade (que pode freqüentemente se apresentar como um naturalismo), aqui representada sobretudo pela busca do bem-estar e pela disposição "terapêutica", tão prevalecente nas religiōes quanto nas psicoterapias.

Velhas e novas Weltanschauungen vão se enovelando na sociedade brasileira, expressando um intenso e desafiador dinamismo cultural, cujo conhecimento é ainda vastamente insuficiente. Colocar lado a lado, como fizemos aqui, as fórmulas que se consideram laicas e as que se consideram religiosas de representação da pessoa e de suas perturbações e terapêuticas parece ser um passo essencial para o esclarecimento desse campo e a interpretação dos processos em curso.

\section{Notas}

1 A circulação anterior da psicanálise no Brasil só pode ser considerada restrita em comparação com o novo período. Podem-se reconhecer diversas iniciativas importantes de divulgação popular, de cuja recepção - no entanto - não se sabe muito. Vale lembrar a difusão bibliográfica e radiofônica (com programas de interpretação de sonhos e apresentação de radionovelas) de Gastão Pereira da Silva (cf. Russo, 2002). Assim também os vários livros sobre educação sexual e psicanálise publicados pela Editora Calvino nas décadas de 1930 e 1940 (ibid.). 
Duarte, L. F. D. \& Carvalho, E. N. Religião e psicanálise no Brasil...

2 A expressão designa o movimento de formação psicanalítica entre cristãos evangélicos. Os responsáveis por esses cursos negam oficialmente qualquer relação direta com o campo religioso, talvez justamente por causa das polêmicas jurídicas com o Conselho Federal de Psicologia e com as sociedades tradicionais de psicanálise. A expressão proposta é conveniente por dois motivos: primeiro porque remete diretamente ao ethos psicanalítico-educacional que está na base lógica da construção teórica, interventiva e de formação profissional desses cursos; segundo porque, na medida em que propõe uma ampla difusão dos saberes e práticas psicanalíticos como um recurso de transformação da sociedade, evoca a referência habitual à psicanálise brasileira da primeira metade do século XX, cuja aliança com os movimentos de educação e higiene mental é bem conhecida.

3 Só em nível de pós-graduação, há no Brasil 78 cursos considerados como de "psicologia" (variando de "teoria psicanalítica" a "neurociências" ou "psicobiologia"); no mesmo nível, há sete cursos de psiquiatria (variando de "saúde mental" a "neuropsiquiatria"), cf. CAPES/MEC (2005).

4 Embora o modelo agostiniano original da psicomaquia cristã também seja conflitivo, com base na libido oriunda do pecado original, a chave positiva se encontra na dimensão consciente, ética, do sujeito e não em suas determinações obscuras.

5 " $[. .$.$] Seu corajoso Pfister me enviou um artigo que hei de agradecer com vagar. A$ atitude dele - um pastor protestante - é de fato louvável, embora para mim seja meio desconcertante ver a Psicanálise arrolada na luta contra o 'pecado'”. Carta de Freud a Jung, 17/1/1909 (apud Drabik, 1984).

6 Esse é o caso de uma informante batista de Juliana Jabor, profissional de classe média, que considera os pentecostais fundamentalmente justos, mas ainda incapazes de usufruir de uma religiosidade superior, mais "amadurecida" - como a sua (cf. Jabor, 2003).

7 No plano jurídico, três confrontos ganharam maior visibilidade nos meios de comunicação. O primeiro teve início em 1998 e corresponde à batalha jurídica empreendida pelo Conselho Federal de Psicologia (CFP) contra a Sociedade Psicanalítica Ortodoxa do Brasil (SPOB), acusando esta de "propaganda enganosa e abusiva" ao prometer formar psicanalistas aptos a exercer a profissão. O segundo corresponde aos projetos de lei de regulamentação da psicanálise e aos investimentos do CFP e das sociedades e associaçõos psicanalíticas contra os mesmos -3/4 refiro-me aqui a dois Projetos de Lei: o PL 3994/2000, de autoria do então deputado 
federal Éber Silva (ex-PDT/RJ), que também é pastor da Igreja Batista; e o PL 2347/2003, de autoria do deputado federal Simão Sessim (PP/RJ). O terceiro confronto de grande repercussão é de ordem estadual e refere-se a um programa estadual de "tratamento e cura" da homossexualidade, a ser financiado pelo estado sob a forma do Projeto de Lei 717/2003, apresentado à Assembléia Legislativa do Rio de Janeiro pelo deputado estadual pelo PSC Édino Fonseca (que é também pastor da Assembléia de Deus).

8 É interessante notar a esse respeito que os quadros docentes dos recentes cursos didáticos de psicanálise apresentam um número considerável de psiquiatras formados na década de 1970. Além disso, a organização do CPPC em 1976 coincide com um período de grande difusão e institucionalização da psicologia e da psicanálise, com todas as intensas disputas territoriais que isso implicou entre psiquiatras e psicólogos.

9 Mesmo os dois primeiros tópicos (inconsciente e sexualidade), tal como tematizados pela psicanálise, puderam ter afirmada sua afinidade com a tradição cristã, em particular por Michel Foucault (cf., sobretudo, Foucault \& Sennett, 1981).

\section{Bibliografia}

\section{ACADEMIA BRASILEIRA DE PSICOLOGIA}

2005 "Academia Brasileira de Psicologia", disponível em <http://www.psicologia. org.br>. Acesso em 19/11/2005.

AMARAL, L.

2000 Carnaval da alma: comunidade, essência e sincretismo na Nova Era, Petrópolis, Vozes.

BAHMANPOUR, $S$.

2003 "The religion of human rights and other religions: are they compatible?" Disponível em <http://www.ihrc.org.uk/>. Islamic Human Rights Commission. Acesso em 20/11/2005.

BELLAH, R.

"Civil Religion in America", Daedalus, 67. 
Duarte, L. F. D. \& Carvalho, E. N. Religião e psicanálise no Brasil...

BEZERRA JR., B.

2002

"O ocaso da interioridade e suas repercussões sobre a clínica", in PLASTINO, C. A. (org.). Transgressōes, Rio de Janeiro, Contracapa Editora, p. 229-38.

BIRMAN, J.

1984

"Sobre a correspondência de Freud com o pastor Pfister", Religiāo e Sociedade 11/2, outubro, Rio de Janeiro.

BIRMAN, P.

1996

"Cultos de possessão e pentecostalismo no Brasil: passagens", Religiāo e Sociedade, 17, p. 90-109, Rio de Janeiro.

BLOCH, A.

2001

"Os psicogélicos", O Globo, Rio de Janeiro, 15/4. Disponível em <http:// oglobo.globo.com/literatura/15lit10.htm>. Acesso em 15/1/2005.

CAPES/MEC 2005

"CAPES/MEC" Disponível em <http://www.capes.gov.br/capes/portal/>. Acesso em $15 / 11 / 2005$.

DRABIK, G.

1984

"Com minhas melhores lembranças, cordialmente (seleção da correspondência entre Freud e Jung)", Religião \& Sociedade, 11/2, Rio de Janeiro.

DUARTE, L. F. D.

1983

"O culto do eu no templo da razão", Boletim do Museu Nacional (Nova Série), 41 [Três Ensaios Sobre Pessoa e Modernidade], 1-69, Rio de Janeiro.

2000 "Person and psychologization in Brazil: a study in moral regulation", Journal of Latin American Anthropology, 4/5 (2/1).

DUARTE, L. D., JABOR, J.; GOMES, E. C. \& LUNA, N.

2006 "Família, reprodução e ethos religioso - subjetivismo e naturalismo como valores estruturantes", in DUARTE, L. F. D.; HEILBORN, M. L.; LINS DE BARROS, M. \& PEIXOTO, C. (orgs.), Família e religiāo, Rio de Janeiro, Contracapa. 
Revista de Antropologia, São Paulo, USP, 2005, v. 48 No 2.

DURKHEIM, É.

1968 [1912] Les formes élémentaires de la vie religieuse, Paris, Presses Universitaires de France.

FIGUEIRA, S.

1985

"Introdução: psicologismo, psicanálise e ciências sociais na "cultura psicanalítica””, in FIGUEIRA, S. (org.), Cultura da psicanálise, São Paulo, Brasiliense.

FOUCAULT, M. \& SENNETT, R.

1981 "Sexuality and Solitude", London Review of Books, 21(May/June).

FREUD, S.

1976 [1932] “A questão de uma Weltanschauung", in Novas conferências introdutórias à psicanálise, Edição Standard Brasileira das Obras Psicológicas Completas, vol. XXII.

GAUCHET, M. \& SWAIN, G.

1980 La pratique de l'esprit humain (l'institution asilaire et la révolution démocratique), Paris, Gallimard.

HEELAS, P.

1996

The New Age Movement, Oxford, Basil Blackwell.

HENNING, M. F.

2000 "Neuroquímica da vida cotidiana", Cadernos IPUB, VI, p. 123-143, Rio de Janeiro.

HUNTER, J. D.

2000

"When psychotherapy replaces religion", Public Interest 5. Disponível em <http://www.findarticles.com/p/articles/mi_m0377/is_2000_Spring/ ai_61600820>. Acesso em 20/11/2005.

JABOR, J. M.

“"Deus não tem netos": um estudo antropológico sobre ethos religioso e mito familiar", Comunicação à V Reunião de Antropologia do Mercosul, Florianópolis, Brasil. 
Duarte, L. F. D. \& Carvalho, E. N. Religiāo e psicanálise no Brasil...

JAMES, W.

1958 [1902] The Varieties of Religious Experience. A study in human nature, The New American Library.

LEWGOY, B.

2005

"Estilos de vida e modelos de construção de pessoa na recente literatura evangélica”, Comunicação ao XXIX Encontro da Anpocs, Caxambu, Brasil

MAGNANI, J. G. C.

2000 O Brasil da Nova Era, Rio de Janeiro, Jorge Zahar.

MARIZ, C. \& MACHADO, M. D. C.

1994 "Sincretismo e trânsito religioso: comparando carismáticos e pentecostais", Comunicações do ISER (A Dança dos Sincretismos), 45, Rio de Janeiro.

RIEFF, Ph.

1968 The triumph of the therapeutic: uses offaith after Freud, New York, Harper \& Row.

RUSSO, J.

1990 "O lacanismo e o campo psicanalítico no Rio de Janeiro", in ROPA, D. (org.), Anuário Brasileiro de Psicanálise, Rio de Janeiro.

1993 O corpo contra a palavra: as terapias corporais no campo psicológico dos anos 80, Rio de Janeiro, Editora da UFRJ.

1997 "Body Therapists in Rio de Janeiro: Relations Between Social Career and Therapeutic Principles", Curare. Journal for Ethnomedicine, 12, p. 39-46.

1999 "Uma leitura antropológica do mundo "psi”", in JACÓ-VILELA, A. M. et al. (orgs.). Clio-Psyché: histórias da Psicologia no Brasil., Rio de Janeiro, UERJ, NAPE, p. 67-74.

2001 "A pós-psicanálise - entre Prozac e Florais de Bach", in JACÓ-VILELA, A. M.; CEREZZO, A. C. \& RODRIGUES, H. B. C. (orgs.), Clio-Psyche. Hoje. Fazeres e dizeres psi na história do Brasil, Rio de Janeiro, Relume-Dumará, p. 117-23.

2002 O mundo psi no Brasil, Rio de Janeiro, Jorge Zahar.

RUSSO, J. \& PONCIANO, E. T.

2002 "O sujeito da neurociência - da naturalização do homem ao reencantamento da natureza”, Physis. Revista de Saúde Coletiva, 12(2), p. 54-76, Rio de Janeiro. 
Revista de Antropologia, São Paulo, USP, 2005, v. 48 no 2.

SALEM, T.

1992

"Manuais modernos de auto-ajuda: uma análise antropológica sobre a noção de pessoa e suas perturbações", Série Estudos em Saúde Coletiva (IMS/UERJ), 7, p. 34, Rio de Janeiro.

SANCHIS, P. 2006

"A Igreja Católica no Brasil e a dimensão do 'sujeito', in DUARTE, L. F. D.; RUSSO, J. \& VENÂNCIO, A. T. (orgs.). A psicologização no Brasil. Atores e autores, Rio de Janeiro, Contracapa.

STEIL, C. A. 2006

"Os demônios geracionais. A herança dos antepassados em um contexto católico carismático", in DUARTE, L. F. D.; HEILBORN, M. L.; LINS DE BARROS, M. \& PEIXOTO, C. (orgs.). Família e religião. Rio de Janeiro, Contracapa.

VIDAL, F. 2000

"La psychologie empirique et son historicisation pendant l"Aufklärung", Revue d"Histoire des Sciences Humaines, 2, p. 29-56. 


\begin{abstract}
The role of psychoanalysis in Brazil - both as a knowledge and as an institution - has changed considerably since the end of the 1970s, when its prestige in the social and cultural life of the country had reached its acme. Several recent analyses describe a growingly decentralized, diversified and complex situation; alongside a proliferation of religious and para-religious resources. That process was more obviously connected to the New Age movements, considered as typical of middle-classes, as a variant of psychological culture. The recent growth of Pentecostal sects, mostly in the lower classes, seemed to obey to other cultural premises. Yet, more recently, the emergence of an intense dialogue between Protestantism and Pentecostalism, on one side, and psychoanalysis, on the other, claimed for new research investment. Here, the research by Carvalho on that specific topic and the work by Duarte on the dynamics of religious and lay cosmologies in contemporary Brazil allow for a new integrated interpretation.
\end{abstract}

KEY-WORDS: religion, psychoanalysis, protestantism, pentecostalism, psychologization.

Aceito em dezembro de 2005. 